\title{
O Programa "Brasil Próximo" na região Centro Paulista: uma experiência de cooperação internacional descentralizada
}

The "Brasil Próximo" Program in the central region of São Paulo state: an international decentralized cooperation experience

\section{Le Programme «Brasil Próximo» dans la région centrale de l'état de São Paulo: une expérience de coopération internationale décentralisée.}

\author{
El Programa "Brasil Próximo" en la región central del estado de São Paulo: una \\ experiencia de cooperación internacional decentralizada
}

\author{
Helena Carvalho De Lorenzo* \\ Sergio Azevedo Fonseca** \\ Larissa Maria Palacio Santos*
}

Recebido em 05/04/2016; revisado e aprovado em 22/08/2016; aceito em 27/09/2016

DOI: http:/ / dx.doi.org/10.20435/1984-042X-2016-v.17-n.4(06)

\begin{abstract}
Resumo: Este artigo relata a experiência de um projeto de cooperação internacional descentralizada, o Programa Brasil Próximo, implementado na região Centro Paulista. Os resultados e legados foram avaliados no contexto da literatura sobre cooperação internacional descentralizada e pelo grau de cumprimento dos objetivos. Também permitiram apontar desafios da cooperação descentralizada internacional para o presente caso.

Palavras-chave: cooperação internacional descentralizada; desenvolvimento local; cooperação entre municípios.

Abstract: This article reports the experience of an international decentralized cooperation project, called Programa Brasil Próximo, implemented in the central region of São Paulo State. The results and legacies were evaluated in the context of the literature on international decentralized cooperation and in the degree of achievement of objectives. Also suggested challenges for international decentralized cooperation to the present case.
\end{abstract}

Key words: international decentralized cooperation; local development; cooperation between municipalities.

Résumé: Cet article rapporte l'expérience d'un projet de coopération internationale décentralisée, le Programa Brasil Próximo, mis en œuvre dans la région central de l'Etat de São Paulo. Les résultats et les legs ont été évalués dans le contexte de la littérature sur la coopération internationale décentralisée et le degré de réalisation des objectifs. Également permis défis ponctuelles de la coopération internationale décentralisée à la présente affaire.

Mots-clés: coopération internationale décentralisée; développement local; coopération entre les municipalités.

Resumen: En este artículo se relata la experiencia de un proyecto de cooperación internacional descentralizada, Programa Brasil Próximo, implementado en la región central de la Provincia de São Paulo. Los resultados y legados fueron evaluados en el contexto de la literatura sobre la cooperación internacional descentralizada y en el grado de consecución de los objetivos. También fueron apuntados los desafíos de la cooperación internacional descentralizada para el presente caso. Palabras clave: cooperación internacional descentralizada; desarrollo local; cooperación entre municipios.

\footnotetext{
* Centro Universitário de Araraquara (UNIARA), Araraquara, São Paulo, Brasil.

** Universidade Estadual Paulista “Júlio de Mesquita Filho” (UNESP), Araraquara, São Paulo, Brasil.
} 


\section{INTRODUÇÃO}

A cooperação internacional é um tema que se fortaleceu no pós-guerra, tratada então como ações de caráter assistencialista ou de ajuda unilateral. Mais recentemente, acompanhando as novas tendências das relações internacionais que emergiram com a globalização, envolvendo a descentralização e o renascimento de novas dinâmicas políticas e sociais de base territorial e novas concepções de desenvolvimento e cooperação internacional, o tema foi tomando novos contornos, tendo destaque aí o da "cooperação descentralizada”. Como mostra Aristizábal (2010), os anos 90 são um marco para a retomada de um novo modelo de cooperação para o desenvolvimento, em função dos questionamentos sobre a efetividade dos impactos dos instrumentos clássicos de cooperação na melhoria da qualidade de vida das populações dos países menos desenvolvidos.

Hafteck (2003) já apontava, no início dos anos 2000, que o termo "Cooperação Descentralizada" contemplava diferentes interpretações, sobretudo pelas organizações multilaterais de cooperação. Embora o termo venha ganhando reconhecimento crescente e exista um volume considerável de materiais de referência, disponíveis sobretudo na web, não existe uma única definição para a cooperação descentralizada. Inicialmente concebida como instrumento de ajuda dos países desenvolvidos às regiões mais pobres, a cooperação internacional se caracterizava como uma relação em que os Estados centrais protagonizavam as ações enquanto os interlocutores dos países periféricos (Estado em qualquer das esferas, organizações da sociedade civil e o setor privado) assumiam papel de receptores passivos. Já no final do século $X X$, contudo, o conceito passava a adquirir um novo significado. Como defendem Douxchamps et al. (1996), passou a abranger um conjunto de processos nos quais é assegurada a colaboração, em diferentes níveis de intervenção, entre potenciais agentes econômicos e sociais dos hemisférios Norte e Sul.

O Programa Brasil Próximo se situa nessa última concepção. Foi instituído em 2009, no âmbito do Acordo de Cooperação Descentralizada Brasil Itália, assinado em Roma em julho de 2004. O acordo envolve cooperação tecno-científica e empresarial entre as regiões italianas do Marche, da Toscana, da Úmbria, da Emília Romagna, da Ligúria e o Governo da República Federativa do Brasil. O interesse da parte brasileira por essas regiões italianas, segundo o documento de estabelecimento do acordo, nasce do propósito em conhecer melhor a experiência italiana de planejamento territorial integrado. Trata-se de um tipo de planejamento em que a diversificação produtiva e dos serviços de apoio ao fortalecimento das micro e pequenas empresas, ao cooperativismo e a outras formas associativas de produção têm lugar central. Outras competências italianas, que também despertaram o interesse brasileiro, foram o marketing territorial, a qualificação da oferta de bens e serviços regionais, os projetos de qualidade total e de imagem de excelência territorial, a economia da cultura, e a valorização econômica dos recursos territoriais, num quadro de desenvolvimento sustentável, de diálogo público-privado, de valorização do Terceiro Setor e de construção de sistemas integrados de intervenções e prestação de serviços sociais em nível do território (BRASIL, 2012).

O Programa Brasil Próximo implementou ações de desenvolvimento local em seis estados brasileiros: Amazonas, com o apoio ao desenvolvimento econômico integrado da região do Alto Solimões; Piauí, envolvendo o apoio à promoção dos processos de democracia participativa em políticas sociais na região da Serra das Confusões; Minas Gerais, buscando a criação de um observatório sobre o turismo da Região Mantiqueira; Rio Grande do Sul, focado na cadeia 
de produção do azeite extra virgem em Bagé; Rio de Janeiro, envolvendo o apoio à construção do marco jurídico e dos instrumentos operacionais para o cooperativismo no Brasil; e São Paulo, abrangendo a construção de uma rede integrada de apoio a políticas públicas voltadas para micro e pequenos empreendimentos e desenvolvimento local, no Centro Paulista, objeto específico de avaliação do presente artigo (BRASIL, 2012).

Este artigo relata o percurso e os resultados do Projeto Centro-Paulista, tendo como referência a literatura sobre as características daquela que pode ser tratada como a nova cooperação internacional descentralizada. Do ponto de vista metodológico, o estudo tem natureza qualitativa, com caráter descritivo (do perfil do projeto) e exploratório (pela particularidade do fenômeno e pela impossibilidade de extrapolação dos resultados), e está delineado como um estudo de caso. A coleta de dados foi realizada com base em registros do próprio projeto (relatórios de atividades e de monitoramento apresentados bimestralmente à agência europeia gestora do Programa Brasil Próximo) e na experiência vivida (pesquisa-ação).

O texto está dividido em quatro seções: esta primeira, introdutória; a segunda, na qual é abordado o conceito de cooperação descentralizada com base na literatura e nos documentos sobre o assunto; a terceira aborda a trajetória do Projeto Centro Paulista e as suas linhas de ação. Na quarta e última seção, estão apresentados e analisados os resultados do projeto e os desafios para a cooperação descentralizada internacional.

\section{A COOPERAÇÃO DESCENTRALI- ZADA INTERNACIONAL}

A concepção contemporânea de cooperação descentralizada como instrumento de promoção do desenvolvimento representa uma transformação em relação ao modelo de cooperação assistencial, vigente sobretudo até os anos 1990. A diferença é que o novo modelo de cooperação se torna multilateral, ganhando traços de reciprocidade (DOUXCHAMPS et al., 1996).

A União Europeia foi a primeira a inserir essa modalidade de cooperação em sua agenda, no contexto dos acordos da IV Conferência de Lomé, firmados em 1989 com países da Ásia, Pacífico e Caribe. Os acordos deram origem ao documento "Comisión Europea, Descentralaized Cooperation, Objetives and Methods" elaborado em Bruxelas em 26 de novembro de 1996, no qual a cooperação internacional descentralizada é definida como:

[...] um novo enfoque das relações de cooperação que busca estabelecer laços diretos com os órgãos de representação local e estimular suas próprias capacidades de projetar e levar a cabo iniciativas de desenvolvimento com a participação direta dos grupos de população interessados, levando em consideração seus interesses e seus pontos de vista sobre o desenvolvimento. (EUROPEAN COMMISSION [CE], 1996).

Esses grupos são identificados como autoridades públicas descentralizadas, grupos rurais e locais, cooperativas, sindicatos, instituições de ensino e pesquisa, organizações não governamentais de desenvolvimento, outras associações, grupos e agentes que sejam capazes e desejem contribuir para o desenvolvimento dos países, desde que os agentes e/ ou operações não tenham fins lucrativos (CE, 1996). A União Europeia adota, portanto, a visão ampla de que todas as possíveis entidades de implementação de projetos possam realizar negócios, desde que se envolvam em atividades sem fins lucrativos.

Segundo Romero (2004), desde a revisão, no final do século $X X$, do conceito de cooperação internacional descentralizada, este foi pensado como um tipo particular de ação multilateral, envolvendo 
não apenas ações econômicas. Passou a implicar, também, a utilização de outros instrumentos como a assistência técnica e financeira, a transferência de tecnologia, a formação de recursos humanos, o reforço de capacidades e o desenvolvimento institucional. Para autores como Romero (2009) e Matuvu (2008) o intercâmbio de experiências adquire um papel prioritário nessa nova significação da cooperação.

Hafteck (2003) sintetiza as características da cooperação descentralizada propostas pelos organismos internacionais, afirmando que a essência do conceito repousa em atividades voltadas ao desenvolvimento, com participação direta e financiamento de organizações não governamentais e ainda com parcerias entre agentes internacionais e atores locais. Entre as experiências com esse perfil, merece destaque a do Programa das Nações Unidas para o Desenvolvimento que, em memorando conjunto com a Assembleia das Regiões Europeias, definiu a cooperação descentralizada como um mecanismo que estabelece uma nova modalidade de parceria, firmada entre agentes das esferas pública e privada e focada nas relações diretas entre territórios regionais, em oposição ao modelo que promove a cooperação bilateral em nível nacional (UNITED NATIONS DEVELOPMENT PROGRAMME / ASSEMBLY OF EUROPEAN REGIONS [UNDP/ERA], 2001).

Já a concepção francesa da cooperação descentralizada, também abordada por Hafteck (2003), salienta a importância de "convenções" entre as autoridades locais. Para os franceses, um acordo formal entre um determinado governo local (ou regional) e sua contraparte estrangeira é necessário para que a cooperação descentralizada possa ocorrer. O mesmo autor mostra, ainda, que o Banco Mundial converge com a abordagem francesa, ao exigir parcerias formais entre autoridades locais de diferentes países, que participam de um programa de intercâmbio e de colaboração que visa melhorar as condições econômicas e sociais das respectivas comunidades e melhorar as habilidades e competências dos parceiros envolvidos (HAFTECK, 2003).

A concepção italiana, por sua vez, defende que a cooperação descentralizada deva ser levada a cabo pelas autoridades locais italianas, individualmente ou em consórcio, envolvendo entidades pertencentes à sociedade civil organizada no correspondente território de competência administrativa. A execução pressupõe parceria com instituições congêneres dos países em desenvolvimento, promovendo a participação de representantes da sociedade civil local no processo de tomada de decisões visando ao desenvolvimento sustentável do território (HAFTECK, 2003; ITALIAN MINISTRY OF FOREIGN AFFAIRS, 1999).

Trata-se de definição que reúne vários elementos já encontrados em definições anteriores: o objetivo geral de desenvolvimento sustentável, o conceito de parceria entre as autoridades locais e a noção de território (área de jurisdição de uma autoridade local). Além disso, a sociedade civil, tanto na Itália como no exterior, é vista não só como beneficiária, mas também como protagonista, embora em um quadro impulsionado e formalizado principalmente pelas autoridades locais, preferencialmente no formato de consórcios entre autoridades locais. Isso vem da prática de colaboração "vertical" entre os governos locais e regionais italianos, a fim de melhor atender às necessidades de seus parceiros estrangeiros, dado que os governos locais no exterior apresentam uma distribuição diferente de poderes e funções.

Outro aspecto da cooperação descentralizada, mencionado pela literatura, é a importância do cofinanciamento, implicando a mobilização de recursos de ambas as partes (MALÉ, 2006). Malé (2006) ressalta a importância do envolvimento de atores públicos que estejam vinculados 
à dimensão local ou territorial, para que sejam assegurados o foco em problemas locais e territoriais, a oferta de competências e um know-how às instituições locais, sem recorrer a gabinetes de consultoria ou especialistas externos, o estabelecimento de cooperação a médio e longo prazos, e a garantia de uma relação mais direta com os cidadãos, implicando uma relação mais participativa.

Segundo Dessoti et al. (2008), também devem ser destacadas as dimensões políticas dos projetos de cooperação descentralizada, que podem ter como objetivo o fortalecimento da dimensão local nas agendas nacionais ou regionais, implicando o reconhecimento de que a cooperação descentralizada pode representar um elemento de pressão para uma maior descentralização do Estado (competências e recursos) e para a interferência nas agendas de integração regional. Em sua dimensão de política mundial, a cooperação descentralizada pode contribuir para uma afirmação positiva dos governos locais na definição de estratégias e políticas internacionais e na solução de problemas globais que normalmente são atribuição exclusiva dos Estados centrais. Partindo-se do princípio de que a cooperação descentralizada é um fenômeno que surge da necessidade de intercâmbio de experiências entre os governos locais, em temas de sua competência, e que ela ocorre no contexto de globalização e descentralização do Estado, ela acaba por representar a possibilidade das cidades e regiões se inserirem de forma mais competitiva em âmbito internacional.

Em síntese, o que se depreende das diferentes interpretações e disposições de documentos oficiais de países e agências internacionais sobre o tema é que o conceito de cooperação descentralizada tem se alterado no sentido de valorizar relações mais horizontalizadas. Buscando agrupar diferentes características da cooperação descentralizada, com foco na avaliação do projeto abordado neste artigo, podem ser destacados os seguintes pontos presentes na literatura sobre o tema e nas disposições das agências internacionais: presença de interesses mútuos (entendidos como interesses dos países participantes da cooperação); noção de território (entendido como o envolvimento de áreas de jurisdição das autoridades locais específicas); presença de atores locais (governos locais e atores institucionais); busca de objetivo comum entre os participantes da cooperação (desenvolvimento local); a natureza das atividades realizadas (de intercâmbios e apoios), presença de parcerias (envolvimento das autoridades locais e de instituições públicas e privadas); cofinanciamentos (recursos provenientes de ambas as partes envolvidas no projeto); acordos entre participantes (preferencialmente formais); e capacitação (entendida com esforços para aumentar as competências locais).

O que se propõe, doravante neste artigo, é que essas características sejam tratadas como parâmetros analíticos, para o relato e a reflexão em torno da experiência e da trajetória do Projeto Centro Paulista.

\section{O PROJETO CENTRO PAULISTA}

As atividades do projeto Centro Paulista iniciaram-se em 2009, tendo sua formalização ocorrida em 2010 com a assinatura de acordos de cooperação entre os municípios de Araraquara, São Carlos, Rio Claro, Descalvado, Itirapina, Ribeirão Bonito. O território, não contínuo, deve-se ressaltar, recebeu a denominação de região Centro Paulista que, contudo, não corresponde a nenhuma das regionalizações oficiais do Estado de São Paulo. Em 2013 os municípios de Gavião Peixoto e Jaú passaram a integrar o projeto.

Os objetivos iniciais do projeto foram a identificação e a implementação de ações voltadas ao desenvolvimento local e regional e a construção de uma rede integrada de apoio às políticas públicas voltadas para micro e pequenos 
empreendimentos. De caráter fortemente transversal e regional, a execução do projeto exigia um rigoroso diagnóstico das potencialidades e fragilidades dos municípios, com vistas ao planejamento das ações do projeto. O período previsto para a realização das atividades foi de 2010 a dezembro de 2014.

A Região Úmbria, por meio da agência Sviluppumbria, foi a responsável italiana pelo projeto, tendo como parceiros brasileiros a Presidência da República, o Ministério do Desenvolvimento, Indústria e Comércio Exterior (MDIC), a Caixa Econômica Federal (CEF) e o Serviço de Apoio às Micro e Pequenas Empresas (SEBRAE). Três universidades regionais brasileiras foram agentes locais do projeto: Universidade Estadual Paulista Júlio de Mesquita
Filho (UNESP), Centro Universitário de Araraquara (UNIARA) e Universidade Federal de São Carlos (UFSCar).

Os recursos para o financiamento das atividades do projeto foram provenientes do Ministério de Relações Exteriores da Itália, por meio da agência Sviluppumbria, e do Governo Brasileiro, por meio da Secretaria Geral da Presidência da República. Os municípios parceiros e outras instituições brasileiras participaram em menor escala, contribuindo com recursos humanos e deslocamentos.

O território abrangido (figura 1) está situado na região central do Estado de São Paulo, compondo parte da Região Administrativa Central do Estado; da Região Administrativa de Campinas; e da Região Administrativa de Bauru.

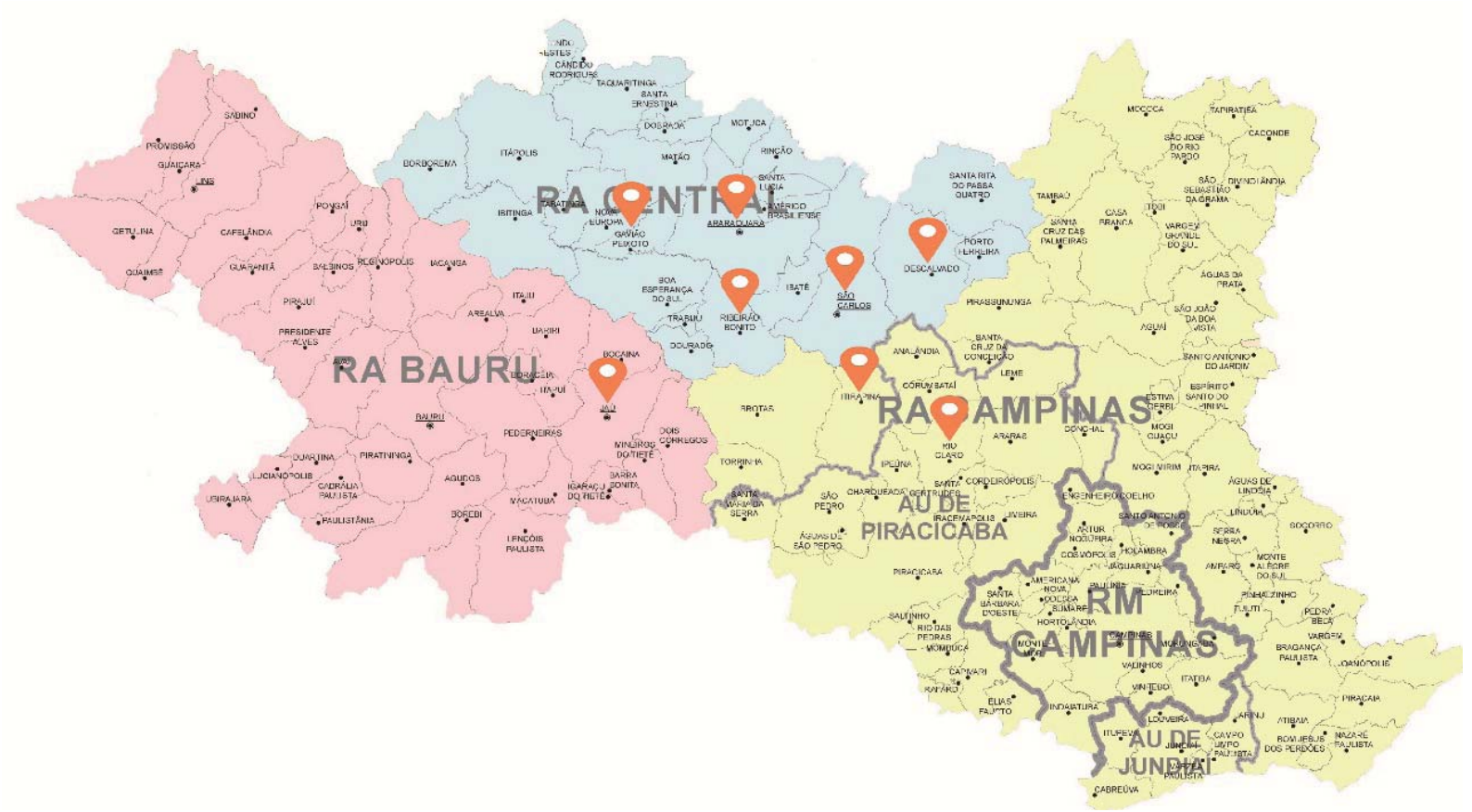

Figura 1 - Território abrangido pela pesquisa

Fonte: Elaboração própria (2015).

De acordo com dados da Fundação Sistema Estadual de Análise de Dados (SEADE, 2016), o território abrangido pelos oito municípios do projeto, conquanto descontínuo, compreende uma área de $5.360 \mathrm{~km}^{2}$, abrigando uma população de cerca de 860 mil habitantes e responden- do por cerca de 2,1\% do PIB do Estado. Do ponto de vista econômico, a região é considerada desenvolvida, quando comparada com outras áreas do Estado. Destacam-se dois importantes segmentos agroindustriais, de processamento de cítricos e de açúcar e álcool (BORGES; 
COSTA, 2005/2006). Na indústria, sobressai o metal mecânico, sobretudo atrelado ao segmento agroindustrial e, mais recentemente, a aeronáutica, em Gavião Peixoto e São Carlos (CARVALHO, 2011; FERNANDES; CÔRTES, 2000). Em Jaú, encontra-se um polo calçadista (GUIDOLIN, COSTA; ROCHA, 2010).

Além dessas atividades, despontam outros segmentos com fortes potencialidades para expansão e integração e constituídos majoritariamente por empreendimentos de pequeno porte, tais como a pecuária (leite, ovinos e caprinos), a fruticultura (como a manga, o limão e a laranja), a indústria de transformação (fármacos, produtos médico-odontológicos e metal mecânica), e o comércio e serviços avançados (CARVALHO, 2011; LOURENZANI; SILVA, 2001).

No tocante à infraestrutura, a região apresenta as seguintes vantagens locacionais: posição geográfica estratégica no MERCOSUL; sistema de transportes e comunicação desenvolvido (rodoviário, aéreo, ferroviário, de telecomunicações); redes digitais abrangentes; sólida base de pesquisa, notadamente em três universidades públicas (USP, UFSCar, UNESP) e em institutos de pesquisa como a EMPRAPA Instrumentação Agropecuária e a EMBRAPA Pecuária Sudeste; serviços de apoio às micro e pequenas empresas com destaque para o SEBRAE-SP; incubadoras de empresas.

Os pontos frágeis seriam: precariedade da integração produtiva em rede, a montante ou a jusante; predomínio do latifúndio, restringindo o espaço da pequena propriedade familiar; baixa cultura inovadora e fragilidade de gestão dos empreendimentos de pequeno porte; restrita atividade turística; escassa cooperação entre universidade e o meio empresarial; escassa cultura cooperativa, na esfera pública ou privada.

Os dados da Fundação SEADE (2016) apontam, também, para uma grande disparidade entre os municípios quanto à renda, ao emprego e às condições sociais, econômicas e ambientais. Embora esteja presente na região uma base institucional capaz de apoiar a incorporação dos processos inovadores pelas empresas, prevalece o distanciamento entre os dois campos. $\mathrm{O}$ propósito do projeto Centro Paulista foi justamente o de contribuir para a quebra dessas barreiras e a redução dessas distâncias e buscar um estilo de desenvolvimento mais harmonioso para a região.

\subsection{A trajetória do Projeto Centro Paulista}

As atividades do Projeto Centro Paulista tiveram início com a identificação de parceiros municipais e regionais e a realização de um diagnóstico de caráter socioeconômico, demográfico, cultural e ambiental. Foram contempladas as especificidades e as condições de cada um dos municípios, identificando, sobretudo, processos recentes com potencialidades de atuação na dinâmica de cada um deles e em sua inserção na região. Para além de caracterizar as atividades de maior relevância em cada município, buscou-se relacionar os segmentos com predominância de empresas de pequeno porte e com potencial de integração regional. Também foram investigadas as organizações, públicas e privadas, atuantes em cada um dos municípios. Para avaliar o potencial da oferta de conhecimentos e de suporte tecnológico, buscou-se identificar, junto às universidades e institutos de pesquisa da região, os laboratórios e grupos de pesquisa capazes de atender às demandas por inovações.

O diagnóstico constatou grandes disparidades entre os municípios e a importância significativa das micro e pequenas empresas, principalmente nos segmentos metal mecânico e de produtos para usos medicinais, hospitalares e odontológicos. No mercado de trabalho, a oferta de postos de trabalho pelos empreendimentos de pequeno porte tem 
destaque em virtude da mecanização da agricultura e da expansão do agronegócio de exportação. Em contraposição, as médias e grandes empresas vêm enfrentando dificuldades para a adoção de sistemas de subfornecimento de âmbito regional que, aliadas à expansão territorial das grandes propriedades agrícolas, representam constrangimentos ao desenvolvimento das pequenas empresas.

Outros fatores, identificados pelo diagnóstico, que limitam o fortalecimento das micro e pequenas empresas, são: as dificuldades de acesso ao crédito; a debilidade dos canais de comercialização dos produtos; o acesso limitado às novas tecnologias e a escassa cultura empreendedora. A insistência na importância desse universo empresarial apoia-se em constatações de que as micro e pequenas empresas podem constituir trajetórias econômicas dinâmicas e bem-sucedidas, desde que dispostas em redes e em um ambiente propício à consolidação de externalidades positivas.

A partir do diagnóstico e frente às dificuldades para a construção de uma forma de cooperação mais integrada entre os municípios parceiros, como a formação de um consorcio intermunicipal (FONSECA; LORENZO 2008), a solução encontrada foi o estabelecimento de um conjunto de ações de âmbito mais limitado, mas ainda próximas do apoio às políticas públicas de integração territorial.

\subsection{As linhas de ação do projeto}

Foram definidas quatro linhas de ação, sintetizadas no quadro 1.

\begin{tabular}{|c|c|c|c|c|c|}
\hline \multicolumn{2}{|c|}{$\begin{array}{l}\text { Objeto de intervenção e } \\
\text { parcerias }\end{array}$} & \multicolumn{4}{|c|}{ Linhas de ação e principais projetos } \\
\hline Municípios & $\begin{array}{l}\text { Instituições par- } \\
\text { ceiras locais }\end{array}$ & $\begin{array}{c}\text { Inovações de } \\
\text { baixa comple- } \\
\text { xidade }\end{array}$ & Empreendedorismo & $\begin{array}{l}\text { Agricultura fa- } \\
\text { miliar }\end{array}$ & $\begin{array}{l}\text { Aglomerados } \\
\text { produtivos }\end{array}$ \\
\hline Araraquara & $\begin{array}{l}\text { Prefeitura, Se- } \\
\text { brae, SENAI }\end{array}$ & $\begin{array}{l}\text { Elaboração de } \\
\text { notas técnicas }\end{array}$ & $\begin{array}{l}\text { Curso empreende- } \\
\text { dorismo jovem. } \\
\text { Apoio à Gestão da } \\
\text { Incubadora de Em- } \\
\text { presas. }\end{array}$ & $\begin{array}{c}\text { Apicultura; en- } \\
\text { velhecimento da } \\
\text { cachaça }\end{array}$ & $\begin{array}{c}\text { Diagnósticos } \\
\text { sobre poten- } \\
\text { cialidades para } \\
\text { aglomerados } \\
\text { produtivos. }\end{array}$ \\
\hline Descalvado & $\begin{array}{c}\text { Prefeitura, } \\
\text { Sebrae, Assoc. } \\
\text { produtores de } \\
\text { leite; Assoc. pro- } \\
\text { dutores de mel }\end{array}$ & $\begin{array}{l}\text { Capacitação } \\
\text { para deman- } \\
\text { das por notas } \\
\text { técnicas }\end{array}$ & $\begin{array}{l}\text { Estímulo ao empre- } \\
\text { endedorismo com } \\
\text { subprodutos do } \\
\text { leite e do mel }\end{array}$ & \begin{tabular}{|c|} 
Capacitação \\
em gestão para \\
agricultores fa- \\
miliares de as- \\
sentamentos da \\
reforma agrária \\
\end{tabular} & \begin{tabular}{|c|} 
Diagnóstico \\
sobre poten- \\
cialidades para \\
aglomerado de \\
produtos Pet
\end{tabular} \\
\hline $\begin{array}{l}\text { Gavião } \\
\text { Peixoto }\end{array}$ & $\begin{array}{l}\text { Prefeitura } \\
\text { municipal }\end{array}$ & & $\begin{array}{l}\text { Projeto de lei das } \\
\text { micro e pequenas } \\
\text { empresas }\end{array}$ & & \\
\hline São Carlos & $\begin{array}{l}\text { Prefeitura } \\
\text { municipal. } \\
\text { ACISC }\end{array}$ & & $\begin{array}{l}\text { Assessoria à Ges- } \\
\text { tão da Incubadora } \\
\text { CEDIN }\end{array}$ & & \begin{tabular}{|c|} 
Diagnósticos so- \\
bre potencialida- \\
des para a cadeia \\
produtiva do \\
segmento produ- \\
tor de sorvetes \\
\end{tabular} \\
\hline Itirapina & $\begin{array}{l}\text { Prefeitura } \\
\text { municipal }\end{array}$ & & $\begin{array}{c}\text { Projeto de lei das } \\
\text { micro e pequenas } \\
\text { empresas } \\
\begin{array}{c}\text { Projeto de estímulo } \\
\text { ao turismo }\end{array} \\
\end{array}$ & $\begin{array}{c}\text { Apoio à reali- } \\
\text { zação de feiras } \\
\text { para comerciali- } \\
\text { zação de produ- } \\
\text { tos da agricultu- } \\
\text { ra familiar. } \\
\end{array}$ & \\
\hline
\end{tabular}




\begin{tabular}{|c|c|c|c|c|}
\hline \multicolumn{2}{|c|}{$\begin{array}{c}\text { Objeto de intervenção e } \\
\text { parcerias }\end{array}$} & \multicolumn{3}{|c|}{ Linhas de ação e principais projetos } \\
\hline Rio Claro & $\begin{array}{c}\text { Prefeitura mu- } \\
\text { nicipal; Assoc. } \\
\text { produtores de } \\
\text { mel }\end{array}$ & $\begin{array}{c}\text { Apoio à tran- } \\
\text { sição agroeco- } \\
\text { logica; selo de } \\
\text { qualidade. }\end{array}$ & \\
\hline Jaú & $\begin{array}{c}\text { Prefeitura muni- } \\
\text { cipal; Sindicato } \\
\text { da indústria } \\
\text { calçadista; Fa- } \\
\text { tec-Jaú }\end{array}$ & $\begin{array}{c}\text { Criação e instalação } \\
\text { de duas incubado- } \\
\text { ras de empresas. }\end{array}$ & $\begin{array}{c}\text { Diagnóstico e } \\
\text { elaboração de } \\
\text { cartilha sobre o } \\
\text { perfil da indús- } \\
\text { tria calçadista de } \\
\text { Jaú }\end{array}$ \\
\hline
\end{tabular}

Quadro 1 - Principais intervenções do Projeto Centro Paulista nos municípios

Na primeira linha de ação, buscando cumprir a expectativa de apoiar a diversificação produtiva, valorizando os capitais endógenos, como contraponto aos processos mais tradicionais na região, que historicamente favoreceram a concentração e a atração de grandes investimentos, o projeto investiu no apoio à gestão da Incubadora de Empresas de Araraquara, à época passando por profunda crise, com o objetivo de, além de promover a recuperação da incubadora, estimular inovações. Para tanto promoveu a aproximação entre a incubadora e o Sistema Integrado de Respostas Técnicas da Unesp (SIRT/UNESP). O projeto SIRT/UNESP é um agente de respostas técnicas, vinculado ao Serviço Brasileiro de Respostas Técnicas (SBRT - rede de apoio ao Sistema Brasileiro de Tecnologia - SIBRATEC). A parceria com o SIRT/UNESP começou em 2012 e, já no primeiro semestre daquele ano, começou a gerar os primeiros frutos: o primeiro deles foi a indução de demandas por respostas técnicas, algo até então inédito no âmbito do SBRT; o segundo consistiu na disseminação, junto a segmentos produtivos especializados da região, de um conjunto de respostas técnicas já elaboradas, extraídas do Banco de Respostas do SBRT. Foi dado especial destaque ao segmento de apicultores dos municípios de Descalvado, Araraquara e Rio Claro, com o objetivo de estimular o surgimento de novos negócios que viessem a utilizar o mel como matéria-prima para a fabricação de produtos diversos, sobretudo alimentícios, de bebidas, farmacêuticos e cosméticos. O balanço que pode ser feito da parceria sugere efeitos sinérgicos e virtuosos tanto para a equipe do Brasil Próximo, quanto para a equipe do SIRT. Ambas ampliaram seu raio de atuação, e a própria Incubadora de Araraquara se fortaleceu.

No campo de apoio ao empreendedorismo, segunda linha de ação (Quadro 1), o Projeto Centro Paulista atuou em quatro frentes e em cinco municípios. Em Araraquara foi realizado um curso de capacitação em empreendedorismo, tendo como público alvo jovens alunos do Serviço Nacional de Aprendizagem Industrial (SENAI), núcleo de Araraquara. Em Descalvado foram realizadas reuniões de sensibilização com as associações de produtores de leite e de mel, para divulgar e difundir as possibilidades e alternativas de verticalização e diversificação da produção, sobretudo a partir da criação de novos empreendimentos capazes de produzirem variedades de subprodutos. Em Gavião Peixoto e Itirapina, a equipe do Projeto Centro Paulista elaborou e submeteu, às respectivas prefeituras municipais, projetos de lei da micro e pequena empresa. Ainda em Itirapina, foi elaborado um projeto de incentivo à criação de novos empreendimentos orientados para o turismo local. Finalmente, em Jaú, a equipe passou a assessorar a prefeitura local em dois projetos de criação e instalação de 
incubadoras de empresas no município, uma mista, no distrito de Potunduva, e outra especializada, na indústria calçadista, na própria sede do município.

Na terceira linha de ação, o ponto de partida foi a realização de diagnósticos sobre a produção de leite, cachaça, apicultura e horticultura e olericultura no território do projeto, com ênfase na produção orgânica e agroecológica, com o apoio de técnicos do SEBRAE-SP e de especialistas italianos.

O balanço que pode ser feito das ações de apoio à agricultura familiar mostra que, nos municípios de Descalvado e de Ribeirão Bonito, embora houvesse alguma manifestação de interesse por parte de produtores, o projeto perdeu força por questões políticas: problema com a sucessão na gestão local e mesmo com a cassação de prefeito, como ocorreu em Descalvado. Em Itirapina, a fragilidade da agricultura familiar suscitou a organização de pequenas feiras mensais para exposição dos produtos e incentivo ao artesanato local.

No caso do município de Rio Claro, contudo, os resultados apresentados podem ser considerados bastante positivos. Contando com forte apoio da Secretaria Municipal de Agricultura, o projeto teve significativa atuação no fortalecimento da associação de produtores familiares e na criação de uma Cooperativa de Agricultores Familiares de Rio Claro e região. Outra importante contribuição foi a organização e a implementação de um selo de qualidade de produtos da agricultura familiar, denominado "Selo Brasil Próximo", atividade que exigiu longa preparação para a elaboração de critérios de normalização. O projeto contou também com o apoio de técnicos italianos tanto para as atividades de normalização como do design do selo. Também foi realizada pesquisa sobre o Programa de Aquisição de Alimentos (PAA) e o Programa Nacional de Alimentação Escolar (PNAE) e suas formas de operacionalização no município.
Cabe menção especial à pesquisa sobre a apicultura regional que, de acordo com Paschoalino et al. (2014), é considerada uma atividade cuja importância transcende a dimensão meramente econômica, tendo forte apelo social, pelos vínculos com a agricultura familiar. Segundo os autores, também é "vista como uma atividade com efeitos ambientais promissores, dado o trabalho de polinização (de espécies nativas e cultivadas) efetuado pelas abelhas" (PASCHOALINO et al., 2014, p. 44).

Essas características da apicultura, aliadas à sua presença em todos os municípios da região Centro Paulista, com forte potencial de integração, tanto horizontal quanto vertical, intra e intermunicipal, foram fatores que chamaram atenção do Projeto Centro Paulista. A busca por esses dois tipos de integração sempre esteve na agenda do Programa Brasil Próximo e do Projeto Centro Paulista. Contudo, em que pese a essas virtuoses da atividade apícola, a equipe do Projeto Centro Paulista constatou que os apicultores do território, que mantém a sua atividade na região, podem ser considerados sobreviventes ou integrantes de uma legião de resistência ao padrão de produção agrícola hegemônico na região, marcado pela monocultura e pelo uso intensivo de agrotóxicos. O conjunto das fragilidades e dificuldades enfrentadas pelos apicultores nos municípios da Região Centro Paulista expressaram a premência da formulação e da implementação de medidas de políticas públicas passíveis de contribuírem para o seu fortalecimento na região.

As atividades realizadas pelo Projeto Centro Paulista apontaram para duas possibilidades de intervenções por meio de políticas públicas: a primeira, fugindo ao alcance dos agentes públicos locais, representada por improváveis ações orientadas para mudanças no padrão de produção agrícola regional, sobretudo no que diz respeito à proibição ou, minimamente, ao rigoroso controle do uso de agrotóxicos; 
a segunda, mais ao alcance dos agentes públicos locais, correspondente à criação de infraestruturas locais facilitadoras do processamento e do envasamento do mel, medida essa considerada capaz de agregar valor à produção apícola regional.

A última linha de ação teve como foco dois municípios: Descalvado e Jaú. Em Descalvado a equipe do Projeto Centro Paulista ofereceu apoios à prefeitura na elaboração de estudos para avaliar a potencialidade e as possibilidades do município vir a se caracterizar como um polo de produtos e serviços para animais domésticos (polo Pet). Isso, em virtude de o município já concentrar algumas grandes empresas fabricantes de produtos dessa linha. Os resultados não foram muito alentadores. Já em Jaú. a equipe, em parceria com a Faculdade de Tecnologia de São Paulo (Fatec) e com o Sindicato da Indústria de Calçados de Jaú (Sindcalçados), fez uma pesquisa de campo e elaborou uma cartilha sobre o perfil da indústria local, com o propósito de fornecer subsídios para a formulação de uma política municipal de apoio à indústria. Foram apresentadas as seguintes sugestões: fortalecimento do tecido associativo; capacitação em gestão financeira, mecanismos e instrumentos de crédito e financiamentos, gestão contábil, custos e formação de preços; capacitação para a exportação; qualificação da força de trabalho; capacitação em gestão ambiental; capacitação para inovações de baixa complexidade; apoio ao empreendedorismo.

\section{RESULTADOS DO PROJETO E DESAFIOS DA COOPERAÇÃO DESCENTRALIZADA}

A formulação e a trajetória do projeto, as características das ações realizadas, além dos resultados alcançados, evidenciam virtudes e dificuldades que se apresentaram a partir de uma compreensão mais ampla do desenvolvimento local e da cooperação internacional descentralizada.
Um dos condicionantes apontados pela literatura, em particular no que diz respeito ao modelo italiano de cooperação, foi observado: a existência de um protocolo formal de intenções firmado, no âmbito do Acordo de Cooperação Descentralizada, entre o Governo Brasileiro e as Regiões Italianas. Foi condição que, no entanto, se mostrou insuficiente para assegurar o efetivo envolvimento dos agentes públicos sub-nacionais com as atividades do projeto: os municípios da região, escolhidos por critérios políticos na oportunidade da assinatura do convênio, comprometeram-se a criar condições para a atuação da equipe do projeto, compromisso esse que não se efetivou para parcela dos municípios que, persistindo imersos no padrão tradicional de desenvolvimento, ficaram fora das ações projeto.

Outro fator crítico para o êxito da cooperação descentralizada em seu novo formato, também presente na literatura, é o referente ao envolvimento ativo dos agentes de cooperação. No caso do projeto Centro Paulista, o intenso comprometimento dos técnicos da agência Sviluppumbria e a experiência acumulada pela equipe local, sobretudo de pesquisadores da universidade em atividades de extensão junto aos municípios da região, constituíram-se em elementos chave para a sustentação das atividades do projeto. Não foram suficientes, contudo, para assegurar o êxito dos resultados: a orientação para a diversificação de atividades econômicas de modo a criar condições para a redução de dependências e fragilidades não encontrou eco satisfatório entre algumas administrações municipais.

Outra questão relativa às dificuldades ou desafios enfrentados pelo projeto refere-se à própria dimensão deste, que se ampliou consideravelmente. O projeto Centro Paulista, em seu início, tinha um foco limitado à seleção de um ou dois temas de interesse regional passíveis de favorecerem a construção de vínculos de 
integração regional entre os municípios parceiros, com base na atuação em segmentos produtivos de micro e pequenos empreendimentos presentes em todos os municípios. O projeto tinha, pois, como foco, a construção de uma estratégia regional de intervenção e de proposição de ações de políticas públicas de âmbito local e microrregional. Propunha-se a construção de políticas públicas com desenhos de baixo para cima, realizados a partir de diagnósticos de potencialidades locais e regionais. Contudo, em razão da baixa cooperação entre os municípios, para cada município houve a necessidade de um projeto específico.

Um exemplo dos desdobramentos dos objetivos foi o caso da agricultura familiar. Observou-se que, embora presente em toda a região, ela não é tratada como prioridade pela maior parte dos municípios. O ideário inovador e as potencialidades da agricultura familiar para a criação de um novo estilo de desenvolvimento apoiado na economia real e no desenvolvimento do território nem sempre são aceitos pelas gestões municipais. Foi possível constatar que a perspectiva de políticas públicas com recorte regional ainda está distante de ser implementada, mesmo em se tratando de segmentos em que todos os municípios têm que atuar, tais como o das políticas federais relativas à segurança alimentar.

Outro caso emblemático foi o do turismo rural. Inicialmente identificado com fortes potencialidades de expansão no município de Itirapina, mas também em Rio Claro, o turismo é uma atividade altamente desorganizada em termos regionais, embora, paradoxalmente, tenha se tornado uma das atividades mais dinâmicas no vizinho município de Brotas. Essa ausência de espraiamento de experiências virtuosas de construção de estratégias de promoção do desenvolvimento territorial sustentável é reveladora, uma vez mais, do fato de que, no Brasil, o insulamento municipal ainda é fator fortemente impeditivo da cooperação, seja entre municípios, seja em âmbito internacional.

\section{CONSIDERAÇÕES FINAIS}

A primeira conclusão que se pode extrair do caso investigado neste artigo é a de que a experiência de cooperação internacional protagonizada pelo Projeto Centro Paulista ligado ao Programa Brasil Próximo preencheu os componentes essenciais da cooperação internacional descentralizada, elencados na seção introdutória deste artigo: evidenciou-se um padrão horizontalizado, flexível e participativo de interações entre as partes envolvidas, apoiado em ações de cooperação e trocas mútuas, sobretudo de conhecimentos, entre os agentes envolvidos; sobressaíram as relações entre esferas subnacionais, contemplando uma maior diversidade de agentes institucionais, inclusive não governamentais; predominou a lógica da criação de condições locais (por meio da capacitação das comunidades) para a construção de estratégias de desenvolvimento duradouras e consentâneas com as características e as especificidades de cada município. A forte participação e o apoio de especialistas e de técnicos italianos da região responsáveis pelo projeto, particularmente da Sviluppumbria SPA, propiciou a oportunidade para o rico intercâmbio de experiências e conhecimentos, especialmente nos processos de capacitação para a agricultura familiar e de apoio ao empreendedorismo, que implicaram ações realizadas por especialistas brasileiros e italianos.

Conquanto se reconheça o valor dessas experiências e da importância da cooperação descentralizada para projetos de desenvolvimento local, pode-se apontar que a heterogeneidade da participação dos municípios no projeto foi a principal razão das divergências entre o que se esperava e o que se alcançou. Já no tocante aos legados do Programa, a avaliação re- 
alizada revelou, de forma inequívoca, que o objetivo central, de formulação, implementação e disseminação de estratégias de promoção do desenvolvimento local ancoradas nos perfis nucleares, sociais, culturais, econômicos, políticos e ambientais, de cada município, foi alcançado de forma satisfatória. Contudo ficam as observações finais de que, no caso do Centro Paulista, ainda é um desafio pensar alternativas concretas de desenvolvimento local que incorporem, além da promoção da atividade econômica, uma dimensão regional e territorial do desenvolvimento, ou seja, algo mais próximo da noção de que o desenvolvimento do território exige a mobilização de energias locais e obriga os governos locais a gerar estratégias de renovação da base econômica e de melhoria na qualidade de vida, de integração social e governabilidade.

\section{REFERÊNCIAS}

ARISTIZÁBAL, A. B. El sistema de la cooperación internacional al desarrollo: evolución histórica y retos actuales. In: TORMO, C. C.; GÓMEZ-TORRES, M. de los (Org.). La cooperación internacional para el desarrollo: edición revisada. Valencia, Espanha: Centro de Cooperación al Desarrollo / Editorial Universitàt Politècnica de Valencia, 2010. (Cuadernos de Cooperación para el Desarrollo n. 1).

BORGES, A. C. G.; COSTA, V. M. H. M. A. Evolução do agronegócio citrícola paulista e o perfil da intervenção do estado. Revista Uniara, n. 17/18, p. 101-123, 2005/2006.

BRASIL, Secretaria Geral da Presidência da República, Secretária-Executiva do Programa de Cooperação Brasil Próximo. Programa de cooperação Brasil Itália: Experiências e Resultados 2003/2010. Brasília, 2012. Disponível em: <http://www.brasilproximo. com>. Acesso em: 20 ago. 2014.

CARVALHO, T. S. Desenvolvimento regional: a economia dos municípios das regiões administrativas central e de Campinas. 2011. Trabalho de Conclusão de Curso (Bacharelado em Ciências Econômicas) - Faculdade de
Ciências e Letras, Universidade Estadual Paulista, Araraquara, SP, 2011.

DESSOTTI, R.; SOUSA, M. A.; MATTIOLI, T. Programa URBAL: Programa URBS América Latina: objetivos, origem e resultados iniciais. In: Relatório Científico Projeto: Gestão Pública e Inserção Internacional das Cidades. São Paulo: CEDEC/PUC/UNESP, 2008. Disponível em: <http://www.observ-ocd. org/LibreriaPagina.asp?id=598>. Acesso em: 13 nov. 2015.

DOUXCHAMPS, F.; BARON, B.; BEAUFORT, D.; BOSSUYT, J.; CROMBRUGGHE, G.; SCHMITZ, J. L.; STAMPA, N. Decentralized cooperation a new european approach at the service of participatory development methodological study. Bruxelas, 1996. Disponível em: <http:/ / aei.pitt.edu/35990/1/A2254.pdf>. Acesso em: 20 ago. 2014.

EUROPEAN COMMISSION (CE). Lome' IV Convention as revised by the agreement signed in Mauritius on 4 November 1995. The Courier, n. 155, 207p., jan./fev. 1996.

FERNANDES, A. C.; CÔRTES, M. R. Caracterização da base industrial do município de São Carlos. Planejamento e Políticas Públicas, n. 21, p. 167-210, 2000.

FONSECA, S. A.;LORENZOH.C. A promoção do desenvolvimento local apoiada em redes de municípios: a experiência do Consórcio Intermunicipal Centro Paulista. Interações Revista Internacional de Desenvolvimento Local, Campo Grande, MS, v. 9, n. 1, p. 55-63, 2008. FUNDAÇÃO SISTEMA ESTADUAL DE ANÁLISE DE DADOS (SEADE). Informações dos municípios paulistas. São Paulo: SEADE, 2016.

GUIDOLIN, M. S.; COSTA, A. C. R.; ROCHA, E. R. P. Indústria calçadista e estratégias de fortalecimento da competitividade. BNDES Setorial, Rio de Janeiro, n. 31, p. 147-184, 2010.

HAFTECK P. An introduction to decentralized cooperation: definitions, origins and conceptual mapping. Public Administration and Development, v. 23, n. 4, p. 333-345, 2003.

ITALIAN MINISTRY OF FOREIGN AFFAIRS. La Cooperazione Decentrata allo Sviluppo. Roma, 1999. Disponível em: <http://www. cooperazioneallosviluppo.esteri.it/pdgcs $>$. Acesso em: 20 ago. 2014 . 
LOURENZANI, W. L.; SILVA, C. A. B. Os desafios da agroindústria de pequeno porte. In: INTERNATIONAL CONFERENCE ON AGRI-FOOD CHAIN, 3. Anais... 2001. Disponível em: <https://www.researchgate. net/profile/Wagner_Lourenzani / publication/228785208_Os_desafios_ da_agroindstria_de_pequeno_porte/ links/0deec526a5235f04ce000000.pdf >. Acesso em: 9 ago. 2016.

MALÉ, J. Especificidades de la Cooperación Descentralizada Pública: Atores, Contenidos y Modelos. In: CONFERÊNCIA ANUAL DO OBSERVATORIO DE LA COOPERACIÓN DESCENTRALIZADA UNIÓN EUROPEAAMÉRICA LATINA, 1. Montevideo: Observatório de Cooperación Descentralizada, 2006.

MAtuvu, G. W. Overview of the characteristics of Decentralized Cooperation Between Europe and Africa. In: Contribution of decentralized cooperation to decentralization in Africa. Jul. 2008. Disponível em: <http:// www.euroafricanpartnership.org/old/ contributi/DCStudy-publication-7_08.pdf>. Acesso em: 20 ago. 2014.
PASCHOALINO, A. et al. Limites e possibilidades para a apicultura na região central do Estado de São Paulo. Revista de Administração da UFSM, v. 7, Edição Especial, p. 43-58, 2014.

ROMERO, M. Fundamentos políticos para la construcción de políticas públicas de cooperación descentralizada en Ameríca Latina. Anuario de la Cooperación Descentralizada, Barcelona, 2009. Disponível em: <http:// observ-ocd.org/sites/observ-ocd.org/files/ publicacion/docs/del_huerto.pdf>.

. Poder local y relaciones internacionales en contextos de integración regional. El caso de la red de mercociedades y la Reunión Especializada de Municipios e Intendencias (Grupo Mercado Común). In: VIGEVANI, Tullo et al. (Org.). A dimensão subnacional e as relações internacionais. São Paulo: EDUC; Fundação Editora da UNESP; EDUSP, 2004. p. 403-440.

UNITED NATIONS DEVELOPMENT PROGRAMME (UNDP)/ASSEMBLY OF EUROPEAN REGIONS (AER). Memorandum of understanding. UNDP/AER, 2001.

\section{Sobre os autores:}

Helena Carvalho De Lorenzo: Docente no Programa de Pós-Graduação em Desenvolvimento Territorial e Meio Ambiente do Centro Universitário de Araraquara (UNIARA). E-mail: dtmeioambiente@uniara.com.br

Sergio Azevedo Fonseca: Docente no Departamento de Administração Pública, FCLAR/ UNESP/Araraquara. E-mail: saf@fclar.unesp.br

Larissa Maria Palacio Santos: Mestranda do Programa de Pós-Graduação em Desenvolvimento Territorial e Meio Ambiente, UNIARA. E-mail: dtmeioambiente@ uniara.com.br 